\title{
Comparison of Impact Damage from Spin Pit and Flat Panel Gas Gun Testing
}

\author{
Andy VanderKlok ${ }^{1}$, James Dorer ${ }^{1}$, Ryan Dutour ${ }^{1}$, Andy Stamm ${ }^{1}$, Eryi $\mathrm{Hu}^{2}$, \\ J. Mike Pereira ${ }^{3 *}$, Gary D. Roberts ${ }^{3}$, Robert K. Goldberg ${ }^{3}$, Xinran Xiao ${ }^{1 *}$ \\ ${ }^{1}$ Michigan State University, 2727 Alliance Dr., Lansing, MI, 48910.*email: xinran@msu.edu \\ ${ }^{2}$ China University of Mining \& Technology, Xuzhou, Jiangsu, PRC 221116. \\ ${ }^{3}$ NASA Glenn Research Center, 21000 Brookpark Road, Cleveland, OH 44135.*email: \\ mike.pereira@nasa.gov
}

\begin{abstract}
Gas gun experiments can generate useful data for the design of jet engine containment shields at much lower costs. To replicate the damage modes similar to that on a containment shield in fanblade-out (FBO) testing, the gas gun experiment has to be carefully designed. This work focuses on the design of projectiles. Gas gun experiments were performed for flat composite panel targets with three different projectiles. FBO conditions were simulated using spin pit tests. The damage modes on the flat panels used in the gas gun tests were compared with damage modes on cylindrical composite containment shields used in spin pit tests. The results show that to generate similar damage modes, it is critical to ensure the shape of the projectile used in a gas gun test accounts for the deformation of the released blade during initial contact in the spin pit test.
\end{abstract}

\section{INTRODUCTION}

In aircraft engine design, one of the requirements for certification is to demonstrate the engine's ability to withstand a fan blade-out (FBO) event per 33.94 FAA regulation [Turnberg (2012)]. Traditionally, shields for blade containment are made of metallic materials [Carney et al (2009)]. The analysis and design procedures for metallic containment shields for FBO are relatively mature. In comparison, much less information is available for the design of composite containment systems [Presley (1999)].

There have been a considerable amount of the research into the development of methods for the design of jet engine containment shields [Carney et al (2009), Roberts et al (2009), Pereira et al (2001), Roberts et al (2005)]. A common method relies on simulating the damage on containment shields in FBO event through ballistic impact experiments. This approach is much more cost effective as compared to engine blade-out testing. It was found that the laboratory scale ballistic testing can generate damage modes on targets similar to that of the initial impact by the released blade on a containment shield in engine FBO tests. However, such experiments must be carefully designed. A number of parameters may influence the damage modes, such as (a) the design of the projectile; (b) the orientation and shape of the projectile; and (c) the configuration and orientation of the target. The relationships between the ballistic testing and spin testing have not been thoroughly examined.

Recently, a spin pit testing facility and a single-stage gas gun have been developed at Michigan State University. The spin apparatus allows one to simulate conditions of an engine blade-out test in a controlled manner and to acquire data to improve our understanding of this process. The gas gun is used to perform ballistic impact simulated experiments. These experimental facilities 
enable a systematic investigation of the relationship between ballistic experiments and spin pit tests.

This work aims at the development of a flat panel gas gun testing methodology for the investigation of the initial damage by the released blade in a spin pit test. The current paper investigates the projectile design. In spin pit testing, the released blade has two velocity components: the rotational and translational. In gas gun testing, the projectile has only the translational velocity. To account for the influence of the rotational velocity, three projectile designs were investigated: (I) a blade segment as the baseline; (II) a projectile with a profile determined by an energy-based similitude design: and (III) a pre-bent blade. The oblique angle of the target was also investigated. The damage modes on the panels were compared with that on composite fan cases after spin tests.

\section{EXPERIMENTAL}

\section{Composite Panels and Composite Shields}

Cylindrical composite shields and flat composite panels were made of S2-glass plain weave fabrics with API SC-15 toughened epoxy resin using the vacuum assisted resin transfer molding (VARTM) method.

\section{Spin Pit Set-up and FBO Experiment}

Figure 1 shows the spin testing facility at Michigan State University. The three major components are a vacuum testing chamber, a drive motor, and a testing rig. The cylindrical vacuum chamber has dimensions of $\Phi 1829 \times 1016 \mathrm{~mm}$. The top cover of the chamber has a $720 \mathrm{~mm}$ diameter removable bulkhead for easy installation of small testing articles. Larger articles can also be tested by removing the entire top cover. For FBO testing, two layers of ballistic liners, a steel ring of $63 \mathrm{~mm}$ thickness, and a layer of ballistic rubber bricks of $200 \mathrm{~mm}$ thickness, have been installed in the chamber. For imaging, the chamber is furnished with nine $305 \mathrm{~mm}$ diameter view ports; eight located on top and one on the bottom. The view ports at the top are positioned to have $360^{\circ}$ coverage of the testing article and allow for $3 \mathrm{D}$ digital imaging correlation (DIC) measurement and high speed cameras. This facility enables unprecedented investigations of FBO events.

Figure 3 shows the shaft and rotor assembly with a full set of wedge-shaped blades and the cross-sectional dimensions of the blade. The blades slide into the hub via the dove tail feature and are bolted to the hub. The shaft, rotor and the blades were all made of Ti-6Al-4V.

In FBO testing, one of the blades needs to be released in a controlled manner. The reported blade release methods for FBO experiments include mechanical release system, magnetic blade excitation, pyrotechnic release and notched blade [Lucy et al (1996)]. Pyrotechnic release is the most precise method but it requires complex safety measures that make it impractical in this laboratory. The notched blade method was selected because it is relatively reliable and simple to implement. The notch was introduced near the root of the blade via die grinder. The release speed was predicted using a relationship between the notch depth and the release speed with the consideration of the notch concentration factor [VanderKlok et al (2016)]. In this work, spin pit testing was conducted with either one releasing blade and one balancing blade or one releasing blade and three short balancing blade segments. The drive motor is a BSI Model 6100 air-turbine 
from Barbour Stockwell, Woburn MA. It is rated at $29.8 \mathrm{~kW}$ (40HP) with a max speed of 40,000 RPM. The testing rig includes a shaft, a bearing house and a rotor assembly, Figure 2.

Figure 3 shows the shaft and rotor assembly with a full set of wedge-shaped blades and the cross-sectional dimensions of the blade. The blades slide into the hub via the dove tail feature and are bolted to the hub. The shaft, rotor and the blades were all made of Ti-6Al-4V.

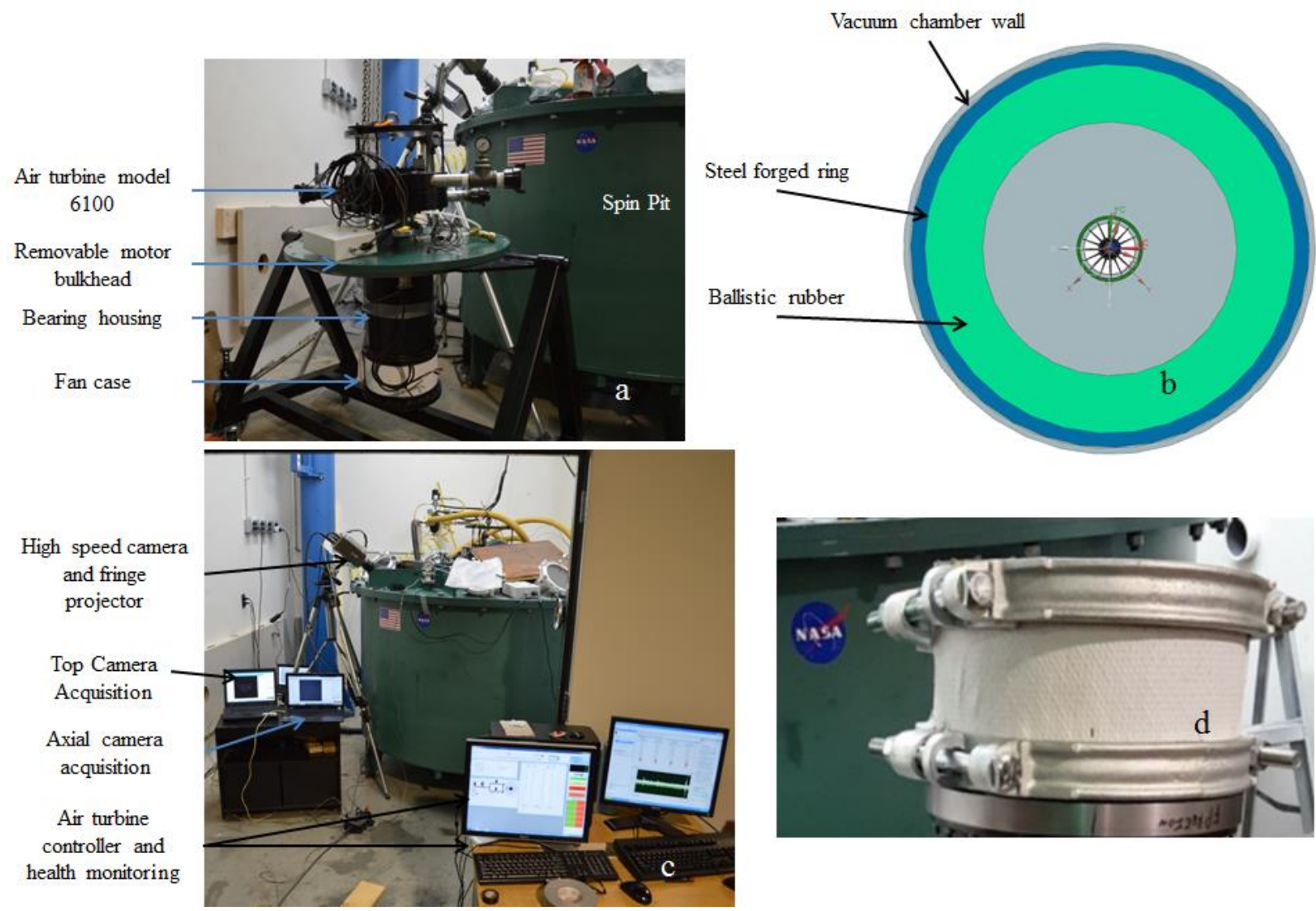

Figure 1. Spin pit test facility: (a) the vacuum chamber and testing rig; (b) schematic of the armored layers inside the chamber; and (c) control and data acquisition during spin testing. (d) A composite containment shield (fan case) is attached by clamps. 


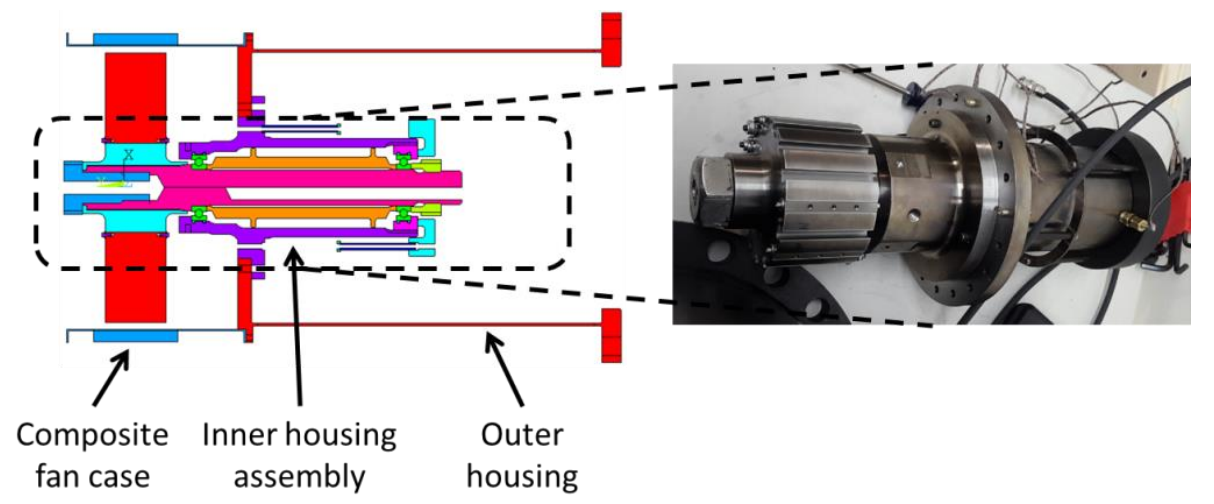

Figure 2. The cross-sectional view of the rotating assembly including bearing house back structure and fan case (left). Assembled inner housing structure (right).
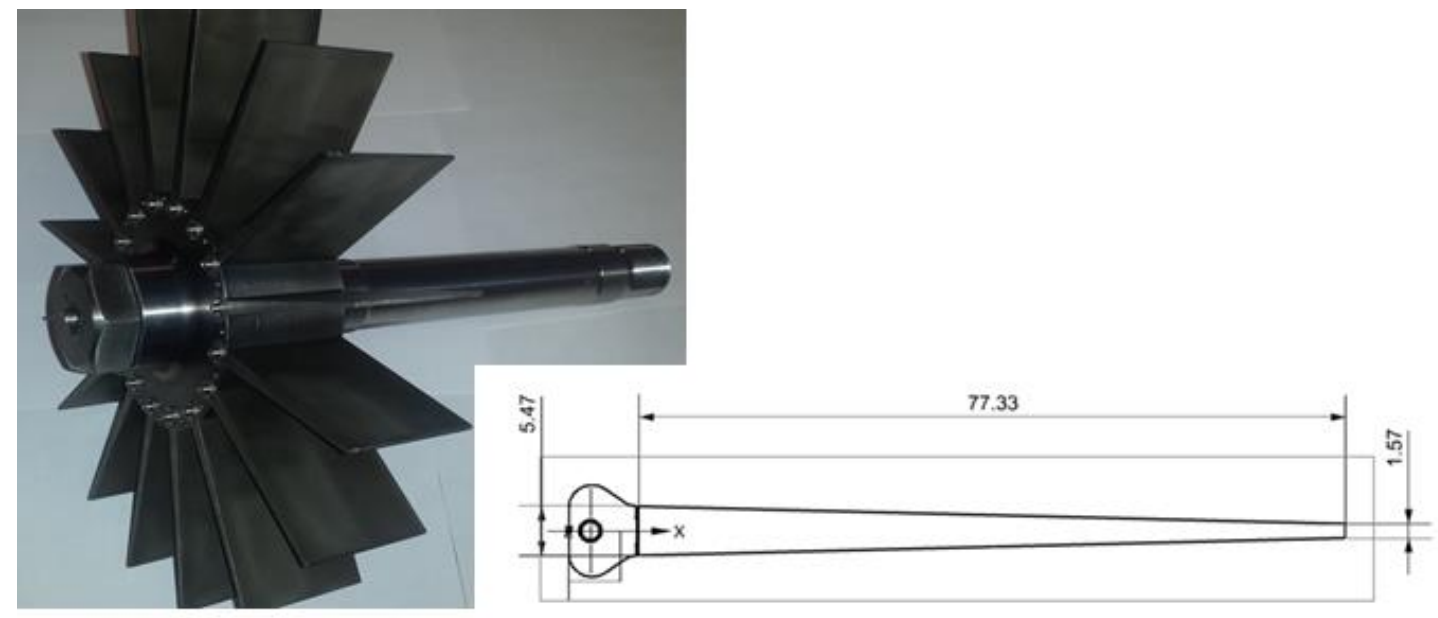

Figure 3. The rotor and shaft assembly with a full set of wedge-shaped blades, and the crosssectional dimensions (in $\mathrm{mm}$ ) of the blade.

\section{Gas Gun Set-up}

Figures 4 and 5 show the schematic and photo of the single stage gas gun used in this work. The major components are a gun barrel, a pressure vessel, and a poppet valve. The steel barrel is $4.7 \mathrm{~m}$ long with an inner diameter of $108 \mathrm{~mm}$. For the tests discussed here compressed helium was used as the propellant. 


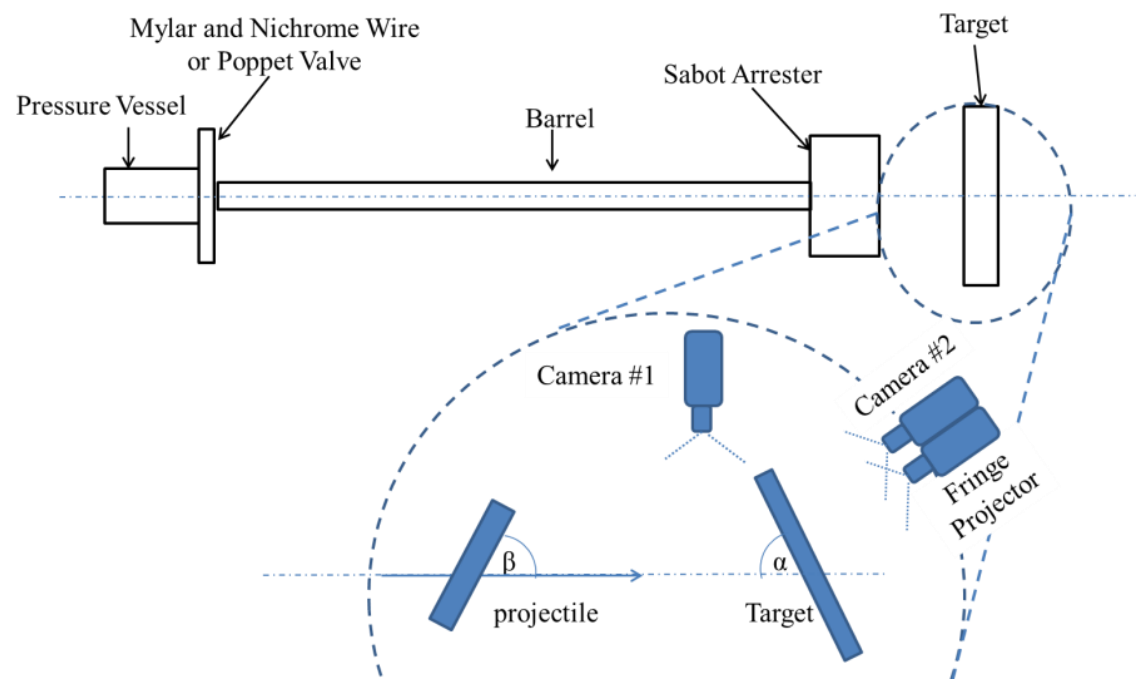

Figure 4. The schematic of a single stage gas gun and experimental set-up.

As illustrated in Figure 4, the target may be placed either $90^{\circ}$ or at an oblique angle $\alpha$ to the gun barrel. The projectile may be oriented parallel or at an angle $\beta$ to the gun barrel. In the current work, the projectile is delivered by a lightweight sabot. A sabot arrester at the end of the barrel destructively stops the sabot and allows the projectile to pass to impact the target. The projectiles used in this work were made of Ti-6Al-4V, the same as the blade in spin test.

Two high speed video cameras were used in the gas gun experiment. Camera \#1, a Phantom V12.1 (Vision Research, Inc., Wayne, NJ), was used to determine the velocity and orientation of the projectile before impact and the residual velocity of a rebounding projectile. Camera \#2, a Phantom V7 was used to determine the residual velocity of the projectile that had perforated the target [Ramadhan et al (2013)] and for out-of-plane deformation using a projection grating profilometry method. The positions of the cameras are shown schematically in Figure 4.

For the gas gun testing, the composite plates were cut to approximately $171.45 \mathrm{~mm} \times 444 \mathrm{~mm}$ with an abrasive diamond face saw. The plate was bolted to a rigid testing fixture through two steel bars, as shown in Figure $5 \mathrm{c}$ and d, to replicate the clamped boundary condition for the fan case in spin testing shown in Figure 1d. The dimensions of the exposed area at the impact side of the panel are $279 \mathrm{~mm} \times 82.55 \mathrm{~mm}$. 

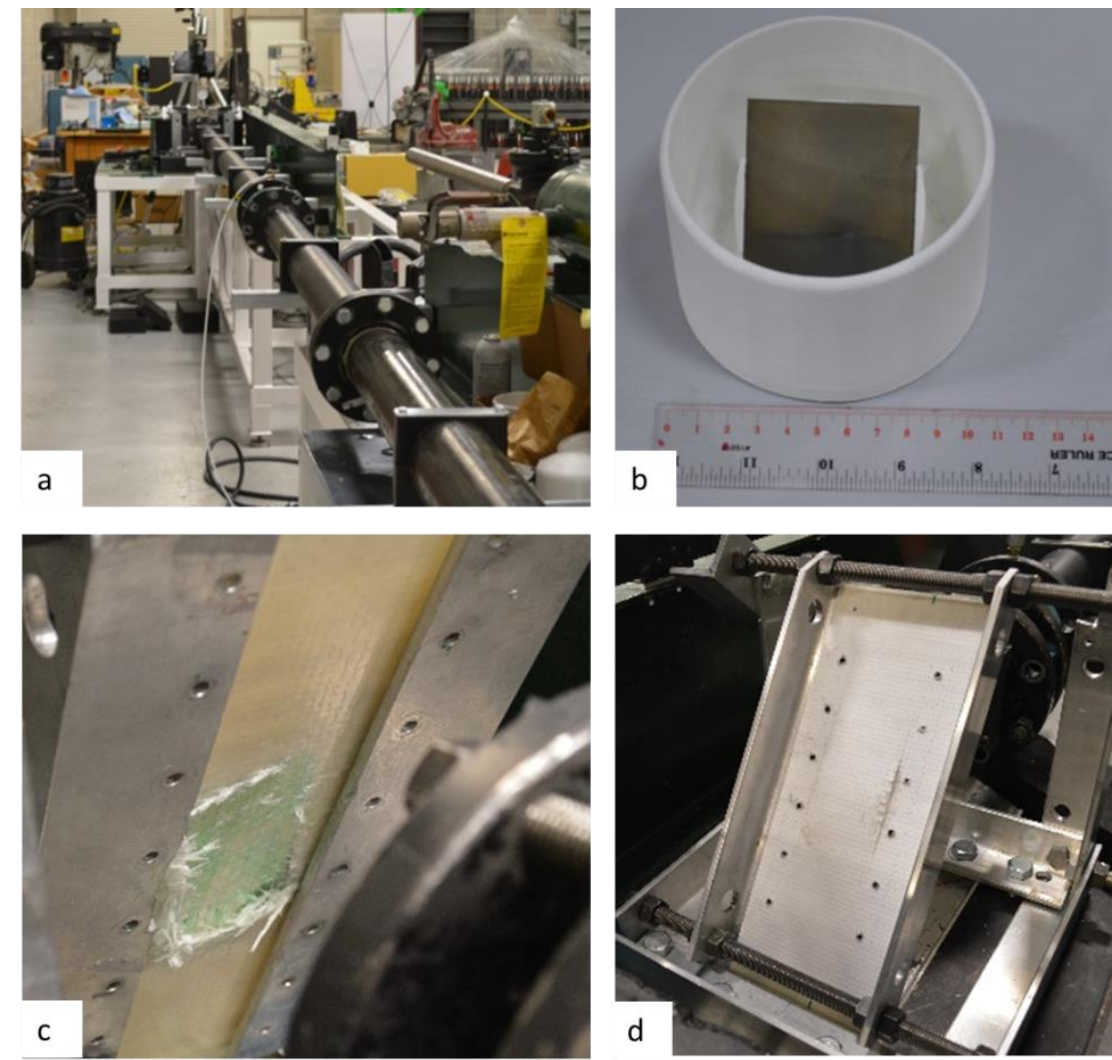

Figure 5. (a) The single stage gas gun. (b) The sabot with a titanium blade secured at a $45^{\circ}$ orientation. (c) The impact side of the panel. (d) The back side of the composite plate is painted white for fringe projection.

\section{PROJECTILE DESIGN FOR FLAT PANEL GAS GUN EXPERIMENTS}

To replicate the observed damage on containment shields from FBO testing using flat panel gas gun testing, three projectile designs have been investigated.

\section{Method I: Blade Segment}

A blade segment identical to the released blade in spin testing is used as the projectile. The impact velocity of the projectile was set to equal to the cg velocity of the blade in spin testing. This method provides the baseline for comparison with alternative designs.

\section{Method II: Energy-based Similitude Design}

Similitude theory allows to scale tests or experiments to a more manageable or simple scenario. It has been explored in impact testing [Jones (1995)] to simulate high velocity impact on plates with low velocity testing. A military standard MIL-P-46593A [Military Specification (1962)] has been developed for the design and fabrication of fragment simulating projectiles (FSP) to simulate the ballistic response of commonly used firearm ammunitions. In the current work, the similitude design is based on matching the energy profile of the blade span by changing the distributed mass of the projectile along its span. Figure 6 presents the thickness profile of the projectile based on this design. 

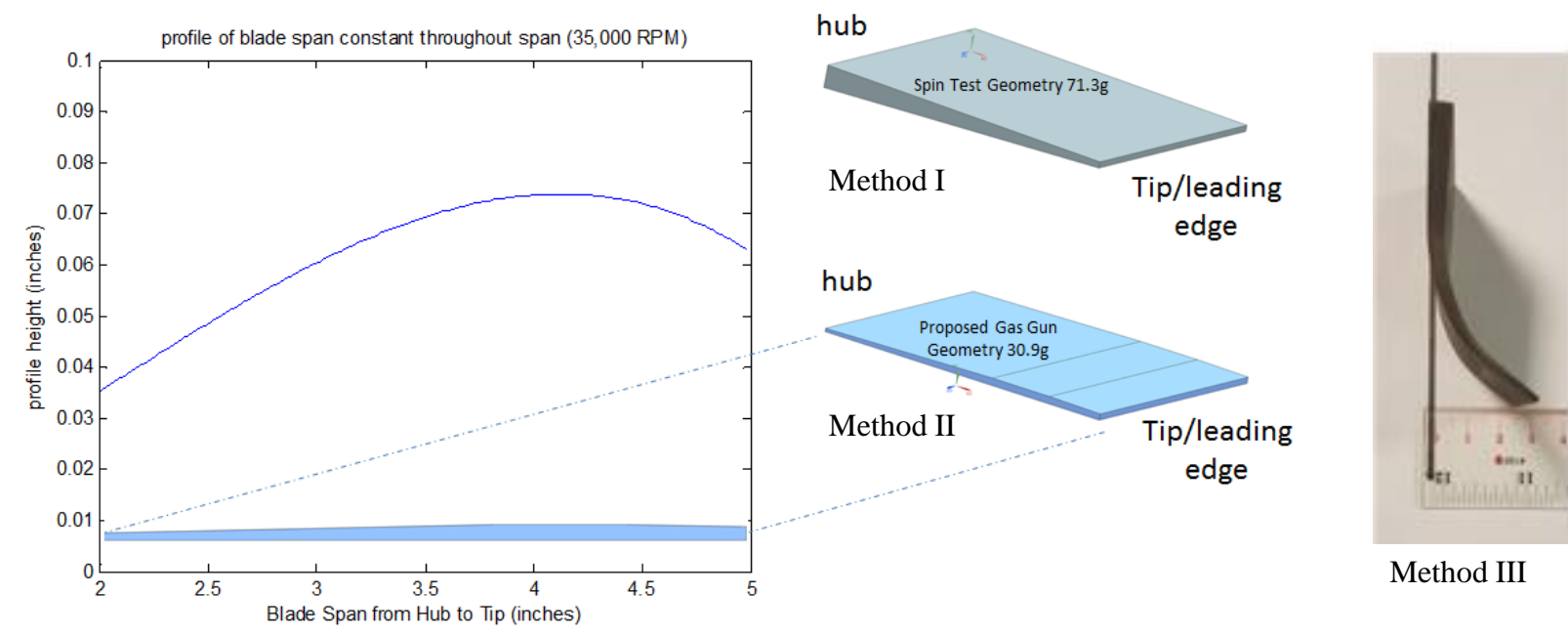

Figure 6. Three projectile designs: I - blade segment; II - energy-based similitude design; III pre-bent blade.

\section{Method III: Pre-bent Projectile}

The deformation and damage of blades and containment shields during FBO from spin pit test depend on many factors such as blade material, blade design, shield material, shield design, and interaction of the released blade with remaining blades. Methods for defining projectile shape and gas gun test conditions using extensive test/analysis correlation has been presented in a previous paper [Roberts (2009)]. Based on the observation that in FBO the initial contact is made by the tip of the released blade, and the blade tip plastically deforms and curls over followed by a second contact of the heavier blade root, the damage caused by the heavier blade root during the second impact is greater than the damage caused by the lighter blade tip during the first impact, a hollow cylindrical projectile was proposed. Following this idea, the current work used a pre-bent wedge to simulate the wedge tip deformation in the spin pit tests. The projectile was made by bending a wedge-shaped blade using a flexural testing fixture with a servo-hydraulic testing frame. Figure 6 shows a pre-bent projectile.

\section{RESULTS AND DISCUSSIONS}

\section{Spin Pit Testing}

FBO tests were performed with five cylindrical composite shields. Table 1 provides a summary for the testing parameters and key characteristics of these tests. In sp_1 and sp_2, the shields were tested with the Al liner. In sp_3, the composite was exposed at the impact zone by removing a strip of $\mathrm{Al}$ of 3 inch wide from the liner circumference. In these three tests, the shield was attached to the bearing house by bolting the liner flange. However, cracks were found at the corner of the flange after the tests. In sp_4 and sp_5, the Al liner was removed completely and the composite shield was clamped directly to the bearing house, as shown in Figure 1d. In the five FBO tests, the blade release occurred in the range of 18,350 to $28,364 \mathrm{rpm}$, corresponding to a tip speed 244 to $377 \mathrm{~m} / \mathrm{s}$. The blade was contained successfully in all tests. 
Figure 7 shows the high speed video footages for sp_2. As seen, the blade makes the first contact with the shield at its tip, which is followed by bending of the blade. The damage on the shield begins as a local event. As the blade bent, the area of contact with the shield increases, delamination and scraping/sliding damages happen next. As the blade is scraping the shield, it starts to pitch, leading to the second impact on the shield with its root.

Table 1. Results of spin tests

\begin{tabular}{|c|c|c|c|c|c|c|}
\hline Test \# & $\begin{array}{l}\text { Fan Case } \\
\text { Type }\end{array}$ & $\begin{array}{l}\text { Design } \\
\text { Velocity } \\
\text { (RPM) }\end{array}$ & $\begin{array}{l}\text { Failure } \\
\text { Velocity } \\
\text { (RPM) }\end{array}$ & $\begin{array}{l}\text { Tip } \\
\text { Velocity } \\
(\mathrm{m} / \mathrm{s})\end{array}$ & $\begin{array}{l}\text { C.G. } \\
\text { Velocity } \\
(\mathrm{m} / \mathrm{s})\end{array}$ & Post Impact Notes \\
\hline sp_1 & $\begin{array}{l}\text { Aluminum } \\
\text { Lined }\end{array}$ & 25000 & 18350 & 244 & 158 & $\begin{array}{l}\text { Contained with minor initial damage from } \\
\text { blade tip. Broken Aluminum liner exposing } \\
\text { composite from blade root interaction. Blade } \\
\text { bent back to nearly } 90^{\circ}\end{array}$ \\
\hline sp_2 & $\begin{array}{l}\text { Aluminum } \\
\text { Lined }\end{array}$ & 25000 & 23284 & 310 & 200 & $\begin{array}{l}\text { Contained with minor initial damage from } \\
\text { blade tip. Broken Aluminum liner exposing } \\
\text { composite from blade root interaction. Blade } \\
\text { bent back to nearly } 90^{\circ}\end{array}$ \\
\hline sp_3 & $\begin{array}{l}\text { Composite } \\
\text { exposed } \\
\text { and bolted } \\
\text { boundary }\end{array}$ & 25000 & 23643 & 314 & 203 & $\begin{array}{l}\text { Contained with majority damage from blade } \\
\text { tip local delamination of at least one layer is } \\
\text { visible on the inner side of case. Outer layers } \\
\text { are bulged but intact }\end{array}$ \\
\hline sp_4 & $\begin{array}{l}\text { Composite } \\
\text { exposed } \\
\text { and } \\
\text { clamped } \\
\text { boundary }\end{array}$ & 30000 & 28364 & 377 & 244 & $\begin{array}{l}\text { Contained with initial contact layer } \\
\text { completely delaminated and sheared along } \\
\text { the edges of the blade. Fibers remain } \\
\text { attached to the fan case. Blade fractured at } \\
1 / 3 \text { distance away from the blade tip. }\end{array}$ \\
\hline sp_5 & $\begin{array}{l}\text { Composite } \\
\text { exposed } \\
\text { and } \\
\text { clamped } \\
\text { boundary }\end{array}$ & 32500 & 25254 & 336 & 217 & $\begin{array}{l}\text { Contained. Inner housing bolt failure } \\
\text { resulting in bolt fragmentation damage on } \\
\text { entire fan case circumference. Scraping and } \\
\text { intial layer delamination from blade tip and } \\
\text { indentation with fiber cutting from blade root }\end{array}$ \\
\hline
\end{tabular}

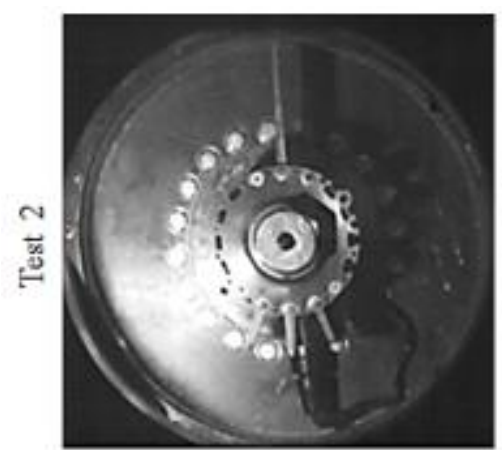

0 us

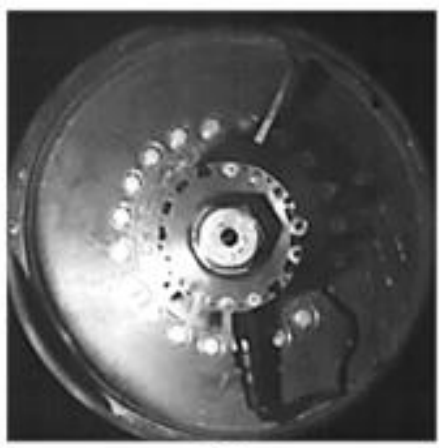

$192 \mu \mathrm{s}$

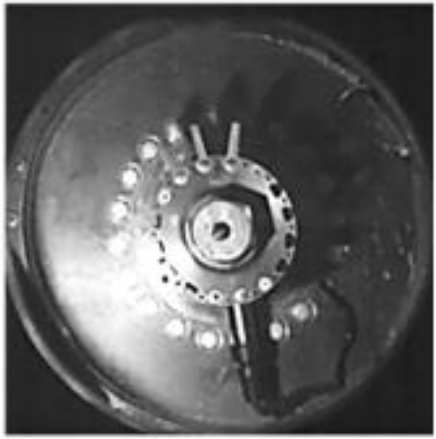

$1115 \mu \mathrm{s}$

FBO Event Timeline

Just before impact

Blade pitching and bending

Blade root impact

Figure 7. High speed images of FBO spin test of sp_2. The rotor rotates clockwise. 
Separated by the blade pitching point, the damage area can be divided into two regions, as shown in Figure 8. In Region i, the blade tip impacts and scraps the shield. In Region ii, the second impact by the blade root takes place. Post-mortem backlighting inspections revealed that the damage on the shield occurs approximately 40\% in Region i and 60\% in Region ii.

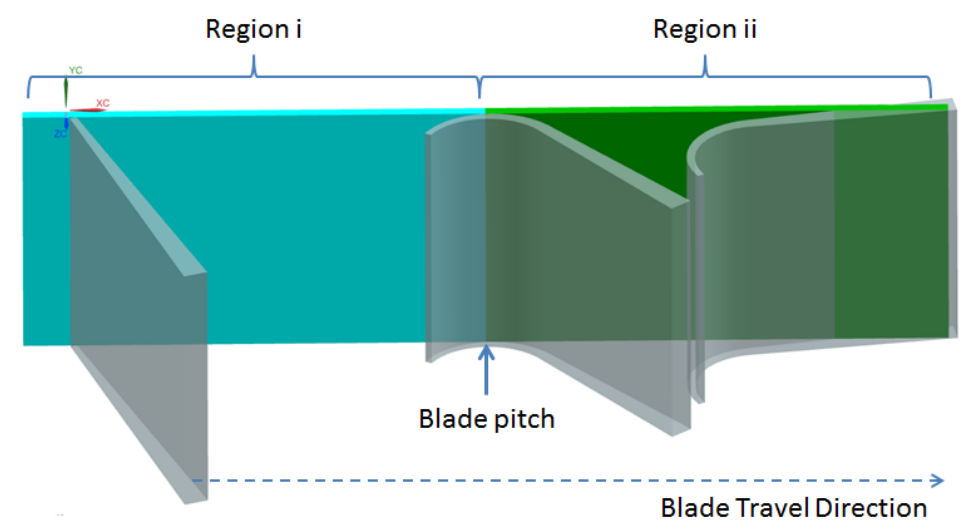

Figure 8. Two damage regions on the shield separated by the pitching point of the blade.

\section{Gas Gun Experiments}

Table 2 summarizes the gas gun experiments. A total of ten experiments were performed with the three projectile designs described in 3.3. The flat panels were tested at three oblique angles $\alpha=34^{\circ}, 45^{\circ}$ and $55^{\circ}$. With the exception of test 5 , the projectile was placed at $\beta=45^{\circ}$ in all tests. As a result, the angle between the tip of the projectile and the panel was at $79^{\circ}, 90^{\circ}$ and $100^{\circ}$, respectively. The other parameters listed are the mass and velocity of the projectile and mass of the sabot. In three experiments, the projectile perforated the panel and the measured residual velocity is reported.

Table 2 also provides the frequency shifts for the $1^{\text {st }}$ and $2^{\text {nd }}$ modes obtained by a frequency measurement for damage evaluation. The frequency shift in the $1^{\text {st }}$ mode, M1, appears to correlate better than M2 with the damage severity determined by visual inspection with backlighting. Hence the damage severity was quantified with a numerical value of 1 to 8 for each tested panel according to its M1 value. The averaged damage severity number was 5.66, 6.00, and 3.25 for panels tested with Method I, II and III, respectively. Judging from the damage severity number, Method I \& II cause more severe damage than Method III.

Good quality high speed images of the gas gun experiments are available for Method I test 3 and Method II test 4, shown in Figures 9 and 10, respectively. In other experiments, the debris from the disintegrated sabot partially blocked the camera views and good quality high speed images are not available for Method III.

Table 2. Summary of the gas gun testing with flat panel

\begin{tabular}{|l|l|l|l|l|l|l|l|l|l|l|l|}
\hline Test & Method & $\begin{array}{l}\text { Pressure } \\
(\mathrm{psi})\end{array}$ & $\begin{array}{l}\text { Target } \\
\text { Orient. } \\
(\text { degree })\end{array}$ & $\begin{array}{l}\text { Proj } \\
\text { Orient. }\end{array}$ & $\begin{array}{l}\text { Mass } \\
\text { Proj } \\
(\mathrm{g})\end{array}$ & $\begin{array}{l}\text { Mass } \\
\text { Sabot } \\
(\mathrm{g})\end{array}$ & $\begin{array}{l}\mathrm{Vi} \\
(\mathrm{m} / \mathrm{s})\end{array}$ & $\begin{array}{l}\text { Vr } \\
(\mathrm{m} / \mathrm{s})\end{array}$ & $\begin{array}{l}\text { N1 } \\
\text { Diff } \\
(\mathrm{Hz})\end{array}$ & $\begin{array}{l}\text { N2 } \\
\text { Diff } \\
(\mathrm{Hz})\end{array}$ & $\begin{array}{l}\text { Damage } \\
\text { Severity }\end{array}$ \\
\hline 1 & $\mathrm{I}$ & 40 & 45 & 45 & 72.1 & 107.9 & 247 & 48 & 9.37 & 12.5 & 8 \\
\hline
\end{tabular}




\begin{tabular}{|l|l|l|l|l|l|l|l|l|l|l|l|}
\hline 2 & II & 70 & 45 & 45 & 28.1 & 104.3 & 377 & 99 & 7.03 & 14 & 7 \\
\hline 3 & I & 39 & 45 & 45 & 71.0 & 104.8 & 220 & - & 2.35 & 25.8 & 4 \\
\hline 4 & II & 71 & 34 & 45 & 29.6 & 105.2 & 290 & 116 & 1.57 & 11 & 3 \\
\hline 5 & II & 70 & 34 & 30 & 28.8 & 105.2 & 329 & - & 9.37 & 18 & 8 \\
\hline 6 & I & 45 & 34 & 45 & 71.5 & 105.5 & 260 & - & 3.12 & & 5 \\
\hline 7 & III & 45 & 34 & 45 & 71.5 & 117.5 & 233 & - & 5.47 & 10.9 & 6 \\
\hline 8 & III & 45 & 45 & 45 & 71.0 & 105.7 & 240 & - & 0 & 37.5 & 1 \\
\hline 9 & III & 45 & 45 & 45 & 71.0 & 104.2 & 232 & - & 2.35 & 14.8 & 4 \\
\hline 10 & III & 50 & 55 & 45 & 72.4 & 106.2 & 238 & - & 0.79 & & 2 \\
\hline
\end{tabular}

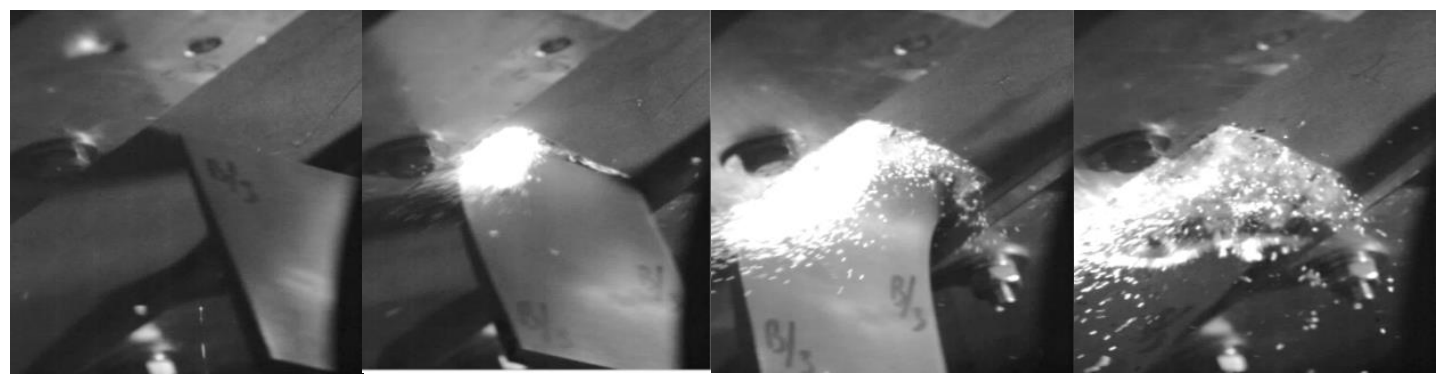

Figure 9. High speed images of the gas gun experiment with Method I, Test 3. From left to right: blade before impact $(0 \mu \mathrm{s})$, tip impact $(115 \mu \mathrm{s})$, blade bending $(346 \mu \mathrm{s})$, and scraping $(653 \mu \mathrm{s})$. The blade tip strikes the panel, bends, and slide on its back.

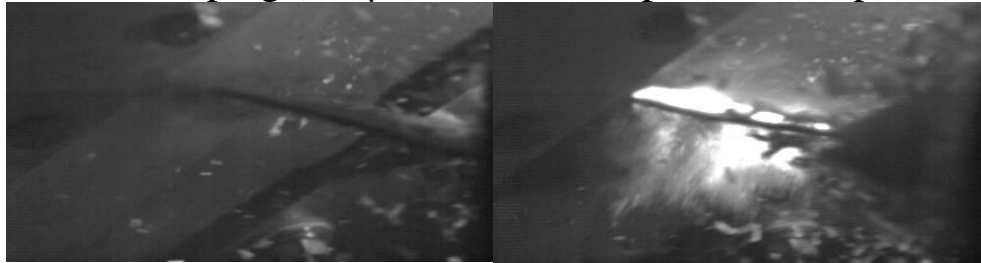

Figure 10. High speed images of the gas gun experiment, Method II, Test 4. The blade tip strikes the panel and goes straight through $(154 \mu \mathrm{s}$ after the left image).

The four images in Figure 9 present a complete process of projectile/panel interaction from the moment of the projectile tip striking the panel, bending of the projectile, to sliding on its back along the target plate. The process is somewhat similar to that seen in FBO in spin testing. Method II, however, produced a different effect. As shown in Figure 10, the projectile pierces through the target panel with little bending.

\section{Comparison of Gas Gun and Spin Tests}

The efficacy of the flat panel gas gun experiment is evaluated by comparing deformed projectiles and damages on the targets with those from spin test. The tested projectiles are compared with the released blades in Figure 11. The images of flat panels under backlighting are compared with that of the composite shields tested in sp_4 in Figure 12.

For Method II, the projectiles deformed in a manner quite different from that of a released blade. The damages on the composite panels are much more localized than that on the composite shields. The results indicate that a projectile with a modified cross sectional shape, although having a similar energy profile as the released blade, may not lead to a similar deformation 
mode. A correct deformation mode of the projectile appears to be more critical in producing similar damage modes on the target.

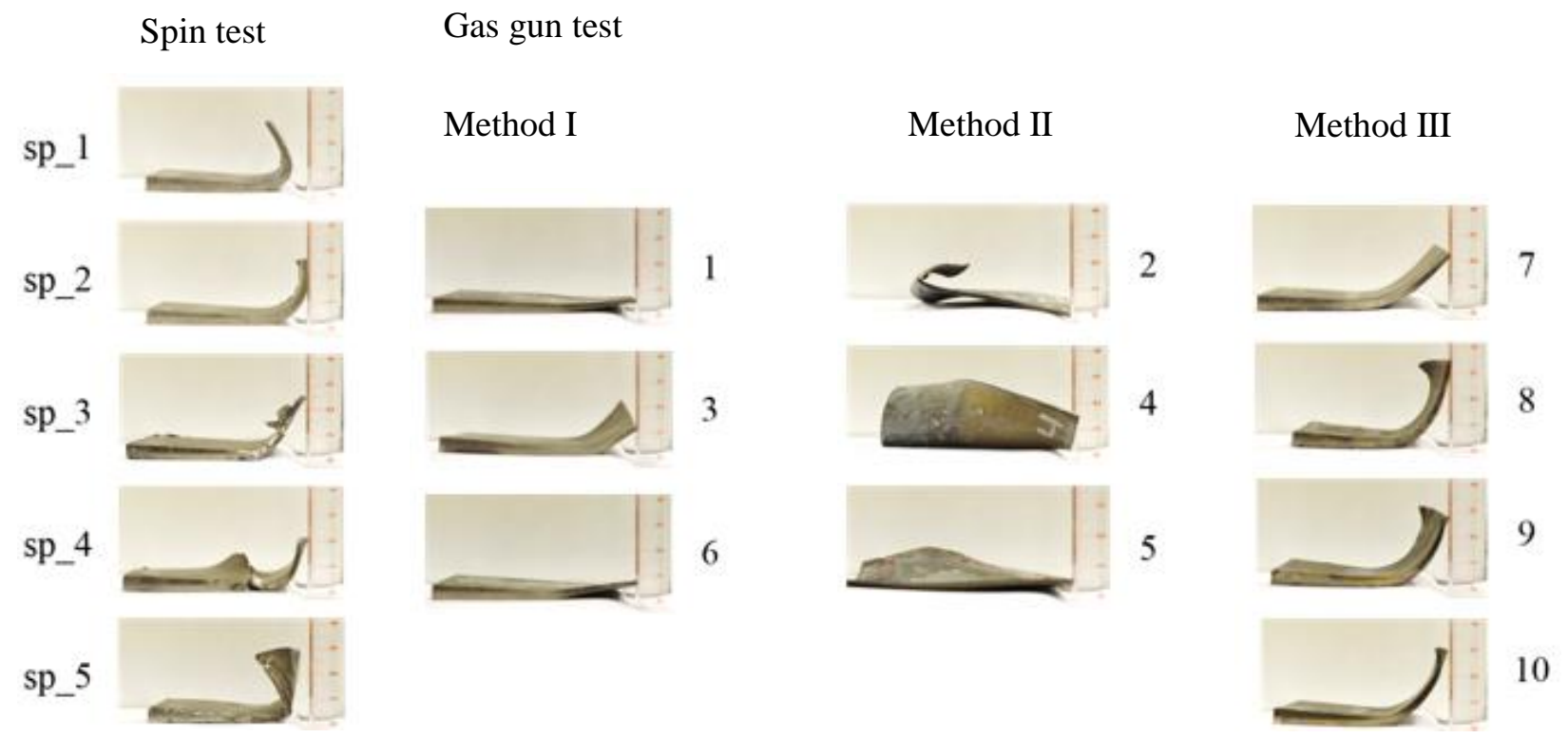

Figure 11. Comparison of released blades from spin tests with the deformed projectiles after gas gun experiments. The scale shown is in centimeter.

For Method I, the results were inconsistent. The projectile from test 3 had a bent shape similar to a released blade in spin test. However, the projectiles from tests 1 and 6 only bent slightly. In test 1 , the panel was perforated although the experiment was designed to simulate spin test sp_4 in which the blade was contained. A close inspection reveals that the failure was initiated by the interaction of the sharp edge of the projectile with the target panel. To reduce this effect, the panel inclination angle $\alpha$ was reduced to $34^{\circ}$ in test 6 . This change reduced the amount of tip damage to the panel. However, the projectile speed in test 6 was slightly over the target speed. The tip perforated the panel causing the projectile to pitch such that its root impacted the panel. There was no scraping or interaction by the mid-section of the projectile, leaving an un-damaged area between the tip and projectile root sections. These result suggest, when the projectile and the target are properly inclined and oriented, a blade segment projectile fired by a gas gun may produce damage modes on a flat panel somewhat close to that on a cylindrical shield in spin test. However, it is difficult to control the exact orientation of the projectile at the time of impact in a gas gun experiment. A small variation can lead to different interactions between the projectile and the target and hence inconstant results.

Method III uses a pre-bent blade as the projectile. This eliminates the possibility of perforation by the sharp tip. Compared with two other methods, the damage severity in Table 2 caused by Method III in general is lower, and the damage revealed by backlighting in Figure 12 spreads over a longer area. The result resembles the damages on the composite shields. 


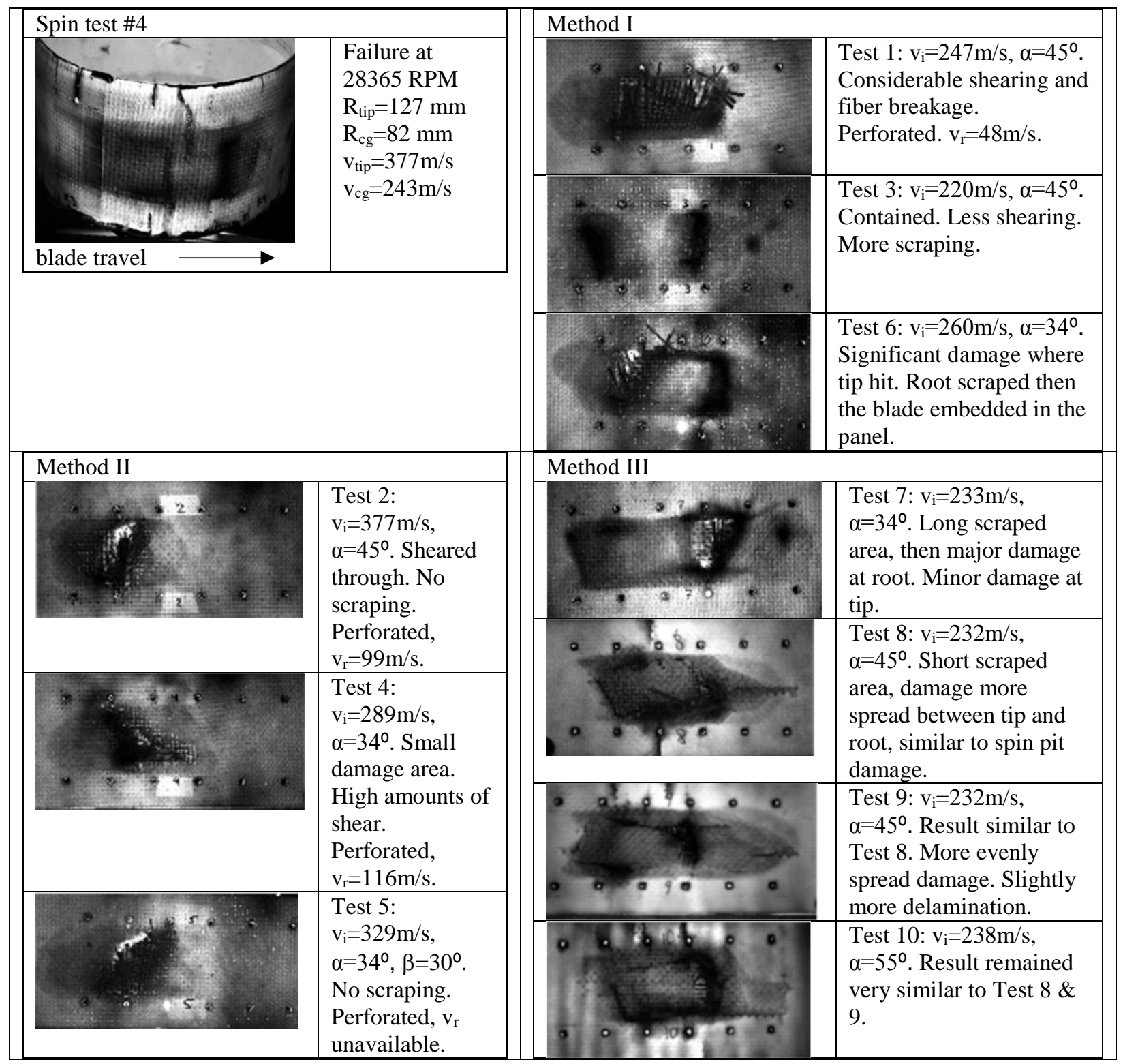

Figure 12. Comparison of damage on composite fan case from spin testing sp_4 with panels after gas gun experiments. Darker regions represent more severe damage.

The Method III was investigated further by varying the oblique angle $\alpha$. It was observed that a low angle of $\alpha=34^{\circ}$ (test 7) resulted in a very long scraping damage in Region $i$ and a sudden impact at Region ii. The second impact caused the formation of a small hole, as very little kinetic energy was absorbed by the panel in Region i. The energy absorbed by Region $\mathrm{i}$ and Region ii can be regulated by varying $\alpha$. Increasing $\alpha$ from $34^{\circ}$ to $45^{\circ}$ in tests 8 and 9 eliminated the penetration by the projectile root, however, it resulted in a very long delamination in Region ii. The backlighting image indicates that the damages by the tip and mid-section of the blade in Region i count for about $30 \%$ of the total damage whereas the rest of $70 \%$ occurred in Region ii. With $\alpha=55^{\circ}$, test 10 resulted in a damage distribution of $40 \%$ in Region $i$ and $60 \%$ in Region ii. In Region i, the main damages observed on the tested panel were broken fibers at the top layer at 
the initial contact point by the blade tip and delamination throughout the region. In Region ii, the layers were sheared through by the impact from the blade root. At the back side of the panel, minor tensile failures occurred along a boundary corresponding to the shape of a blade segment. These failure modes were similar to the damages observed on the composite shield in sp_4.

\section{CONCLUSIONS}

A spin pit testing facility and a single-stage gas gun have been developed. Using these facilities, the hypothesis that flat panel gas gun experiments may produce similar results to substitute spin pit FBO testing was investigated. Cylindrical shields and flat panels made of S2-glass/SC-15 epoxy composite were tested. FBO tests in the spin pit used a wedge-shaped blade. In gas gun experiments, three different projectile design methods were developed and evaluated. The results show that, to produce similar damages on flat composite panels in gas gun experiments as on composite shields in spin test, it is critical to ensure the deformation of the projectile is similar to that of a released blade in spin test. With a pre-bent wedge-shaped blade as the projectile, gas gun tests closely replicated the damages on composites as that from spin testing. The target oblique angle $\alpha$ and projectile orientation $\beta$ also affected the results. The gas gun test with $\alpha=55^{\circ}$ and $\beta=45^{\circ}$ produced the best replica to the spin test. The gas gun testing method presented here provides a cost effective means for accurate pre-screening of composite containment shield materials and designs.

\section{ACKNOWLEDGEMENTS}

This work is supported by NASA Glenn Research Center through grant number NNX12AL14A.

\section{REFERENCES}

Bender, D., Schuster, J., and Heider, D. (2006). "Flow rate control during vacuum-assisted resin transfer molding (VARTM) processing," Compos. Sci. Technol., 66(13), 2265-2271.

Balancing, I. R. D. (2001). Balance quality requirements of rigid rotors: the practical application of ISO 1940/1.

Carney, K. S., Pereira, J. M., Revilock, D. M., and Matheny, P. (2009). "Jet engine fan blade containment using an alternate geometry," Int. J. Impact Eng., 36(5), 720-728.

Grimsley, B. W., Cano, R. J., Hubert, P., Loos, A. C., Kellen, C. B., and Jensen, B. J. (2004). "Preform characterization in VARTM process model development".

$\mathrm{Hu}, \mathrm{E}$. and He, Y. (2009). "Surface profile measurement of moving objects by using an improved $\pi$ phase-shifting Fourier transform profilometry," Opt. Lasers Eng., 47(1), 57-61.

Hibbeler, R.C. (2007). Engineering Mechanics Dynamics, 11th ed. New Jersey: Pearson Prentice Hall.

Jones, N. (1995). "Some comments on several phenomena in structural impact," Am. Soc. Mech. Eng., 153-167.

Kessler, S. S., Spearing, S. M., Atalla, M. J., Cesnik, C. E. S., and Soutis, C. (2002). "Damage detection in composite materials using frequency response methods," Compos. Part B Eng., 33(1), 87-95.

Lucy, M., Hardy, R., Kist, E., Watson, J., and Wise, S. (1996). "Report on alternative devices to pyrotechnics on spacecraft," DTIC Document. 
Meirovitch, L. (1986). Elements of vibration analysis. Singapore, McGraw-Hill. ISBN 0-07041342-8.

Military Specification (1962). "Projectile, Calibers .22, .30, .50, and $20 \mathrm{~mm}$ FragmentSimulating," MIL-P-46593A.

Pereira, J. M. and Lerch, B. A. (2001). "Effects of heat treatment on the ballistic impact properties of Inconel 718 for jet engine fan containment applications," Int. J. Impact Eng., 25(8), 715-733.

Presley, K. L.(1999). “Assessment of an Advanced Containment System.," DTIC Document.

Ramadhan, A. A., Abu Talib, A. R., Mohd Rafie, A. S., and Zahari, R. (2013). "High velocity impact response of Kevlar-29/epoxy and 6061-T6 aluminum laminated panels," Mater. Des., 43, 307-321.

Roberts, G. D., Pereira, J. M., Braley, M. S., Arnold, W. A., Dorer, J. D., and Watson,W. R. (2009). "Design and testing of braided composite fan case materials and components," in 19th International Symposium on Air Breathing Engines, Montreal.

Roberts, G. D., Pereira, J. M., Revilock, D. M., Binienda, W. K., Xie, M., and Braley, M. (2005). "Ballistic Impact of Braided Composites with a Soft Projectile," J. Aerosp. Eng., 18(1), 3-7.

Su, X. and Zhang, Q. (2010). "Dynamic 3-D shape measurement method: a review," Opt. Lasers Eng., 48(2), 191-204.

Salawu, O. S. (1997). "Detection of structural damage through changes in frequency: a review," Eng. Struct., 19(9), 718-723.

Sanders, D. R., Kim, Y. I., and Stubbs, N. (1992). "Nondestructive evaluation of damage in composite structures using modal parameters," Exp. Mech., 32(3), 240-251.

Turnberg, J. (2012). “33-94 Analysis_08_12_FAA_certification.pdf." Federal Aviation Administration.

Takeda, M. and Mutoh, K. (1983). "Fourier transform profilometry for the automatic measurement of 3-D object shapes," Appl. Opt., 22(24), 3977-3982.

VanderKlok, A., Stamm, A., and Xiao, X. (2016). "Fan-blade-out Experiment at Small Scale," Experimental Techniques, 40(6), 1479-1484.

VanderKlok, A. et al. "Investigation of High Velocity Impact Responses of a Glass/Epoxy Composite with a Gas Gun," Under review.

Wilbeck, J. S. (1984). "Tests of spinning turbine fragment impact on casing models," Nucl. Eng. Des., 77(3), 321-329. 